\title{
Study on Influence of Nitrate on Induction of Denitrifying Phosphate Accumulating Organisms
}

\author{
Xiaoling Zhang*, Yanhong Zhao and Zhengqun Li \\ School of Environmental Science and Engineering, Key Laboratory of subsurface Hydrology and Ecological Effects in Arid \\ Region, Ministry of Education, Chang' an University, Xi'an 710064, Shaanxi, P.R. China \\ ${ }^{*}$ Corresponding author
}

\begin{abstract}
The enrichment of denitrifying phosphate accumulating organisms (DNPAOs) is the prerequisite for the denitrifying phosphate removal process. This study investigated the effect of nitrate concentration on the enrichment of DNPAOs was studied with batch experiments. The Sequencing Batch Reactor (SBR) was set-up with acetate as the sole carbon source. The addition of nitrate solution and the anoxic time were gradually increased with time. Denitrifying phosphorus accumulation was observed soon, but the concentrations of nitrite and nitrate in effluent were fluctuated at the beginning. Then adjusting nitrate concentration according to the ratio of phosphate uptake to nitrate consumption get by batch experiment, the removal efficiency of phosphorus and nitrogen reached $95 \%$ and $96 \%$, respectively, and phosphorus concentration in effluent was always lower than $0.5 \mathrm{mg} / \mathrm{L}$ in the following days. It was estimated that the percentage of DNPAOs in total PAOs increased from $27.61 \%$ (before induction of DNPAOs) to $78.61 \%$ (after induction of DNPAOs), by calculating the maximum anoxic or aerobic phosphorus uptake rate under the same conditions.
\end{abstract}

Keywords-DNPAOs; nitrate concentration; induction

\section{INTRODUCTION}

It is well known that excessive phosphorus and nitrogen discharged from domestic and industrial wastewater bring about eutrophication[1].which impairs the quality of the water, which is not satisfied for drinking water source, irrigation, industrial, and so on[2].Nitrogen and phosphorus must be removed from wastewater to meet stringent standards. So far biological nutrient removal (BNR) is a frequently used and environmentally sustainable method. However, there are some contradiction between nitrogen removal and phosphorus removal in the processes of $\mathrm{BNR}$, such as $\mathrm{SRT}, \mathrm{NO}_{3}{ }^{-}$in anaerobic zone, and low $\mathrm{C} / \mathrm{N}$ in wastewater[3]. Especially, the limited carbon source in wastewater will trigger competition between denitrifiers and phosphorus accumulating organisms (PAOs), and then nitrogen and phosphorus hardly satisfied the strict standards.

Since 1980s, there have been many reports claiming that a significant fraction of PAOs could use nitrate instead of oxygen to uptake phosphorus under anoxic environment[4]. Compared with conventional biological phosphorus removal, denitrifying phosphorus removal can lead to a considerable savings in aeration energy and the amount of carbon sources needed for denitrification as well as lower sludge production. Kuba reported that the required COD in a denitrifying phosphorus removal system could be up to $50 \%$ less than for conventional aerobic phosphorus and nitrogen removal systems. Moreover oxygen requirements and sludge production can be decreased in significant amounts of about 30 and $50 \%$, respectively [5].

As we known denitrifying phosphorus accumulating reaction is also a kind of oxidation-reduction reaction, following the same laws of thermodynamics. When the $\mathrm{pH}$ and concentration is constant, the process whether can be carried out or not depends on the standard electrode potential of the oxidant and reductant. The electrode potentials of nitrate, nitrite are both high. So, nitrate or nitrite can replace oxygen as an electron acceptor in phosphorus removal system.

Although biochemical and microbial mechanisms of DNPAOs have not been clarified, it is be accepted that DNPAOs can be enriched by proper configurations. It has been verified that DNPAOs has the metabolic behavior similar to PAOs. Under anaerobic conditions, DNPAOs take up readily biodegradable organic carbon substrates and store them as polyhydroxyalkanoates (PHAs), the energy is derived from the hydrolysis of intracellular polyphosphate and the glycolysis of glycogen followed by the release of ortho-phosphate to the bulk liquid. In the subsequent anoxic phase, DNPAOs use nitrate or nitrite as electron acceptor to oxidize the PHAs for generating energy for growth, glycogen synthesis, and phosphate uptake, where the DPAOs take up phosphate more than released during the anaerobic phase[6].

A number of denitrifying phosphorus removal processes have been developed, such as UCT, BCFs, DEPHANOX and $\mathrm{A}_{2} \mathrm{NSBR}$. they have been demonstrated that the successful key of denitrifying phosphate removal processes is the induction and enrichment of Denitrifying Phosphate Accumulating Organisms (DPAOs), while nitrate concentration plays an important role in the induction of DPAOs. Anoxic phosphorus uptake would not be completed if the nitrate concentration is too low to oxidize PHAs in the bacteria. More electron acceptor can be supplied at higher nitrate concentration, but surplus of nitrate will affect the effluent and the subsequent anaerobic period. So there is a proportional relationship between nitrate concentration and phosphorus concentration in anoxic environment. When the proportional relationship varied, the phosphorus removal efficiency will decrease, although phosphorus uptake is observed at the beginning. 
The aim of this study was to investigate the influences of nitrate concentration on induction of DNPAOs in the lab-scale anaerobic/anoxic SBR reactor.

\section{MATERIALS AND METHODS}

\section{A. SBR System}

A completed stirred laboratory sequencing batch reactor (SBR) was set up and operated at $25^{\circ} \mathrm{C}$ constant temperature. The working volume of SBR was $4 \mathrm{~L}$ and the air compressors were used for aeration. The $\mathrm{pH}$ was adjusted between 7.5 and 8 by buffer; the sludge retention time was kept at 20 days by wasting $200 \mathrm{ml}$ mixed liquid daily. Peristaltic pumps were employed for feeding and withdrawing.

The SBR was inoculated with activated sludge from a full scale plant treating combined industrial and domestic sewage. The SBR cycle changed from anaerobic/aerobic (period 1) to anaerobic/anoxic (period 2) when the traditional phosphorus removal system established. The SBR with the 6-hour cycle consisting of anaerobic phase $(2 \mathrm{~h})$-aerobic phase $(3 \mathrm{~h})$-settling (45 min)-drawing (15 $\mathrm{min}$ ) in period 1 , and with the 6-hour cycle consisting of anaerobic phase $(2 \mathrm{~h}$-anoxic phase $(3 \mathrm{~h})$ settling (45 $\mathrm{min})$-drawing $(15 \mathrm{~min})$ in period 2 . There are 4 cycles in one day and the HRT was 12 hours in both periods.

\section{B. Substrate Compositions}

Synthetic wastewater with a composition of sodium acetate, ammonium chloride, potassium dihydrogen phosphate, and trace element; COD of 200 800 mg/L, PO43--P of $10 \mathrm{mg} / \mathrm{L}$, $\mathrm{NH} 4+-\mathrm{N}$ of $10 \mathrm{mg} / \mathrm{L}$, alkalinity of $350 \mathrm{mg} / \mathrm{L}$, pH 7.5 8.0, was fed in the experiment. Sodium nitrate was fed at the end of anaerbic phase in period 2 .

\section{Batch Experiments}

In order to investigate the ratio of anoxic phosphorus uptake and nitrate consumption, the influences of nitrate concentration during enrichment of DNPAOs, batch experiments were conducted. Two identical serum bottles were used for the batch experiments, each with working volumes of $1 \mathrm{~L}$, respectively. Before starting each batch test, the bottles were filled with 0.5 mixed liquor, withdrawing from the parent reactor at the end of anaerobic period. All batch experiments were conducted during the steady stage of the system, and the temperature was controlled at $25 \pm 1{ }^{\circ} \mathrm{C}$.

\section{Analytic Methods}

Samples of effluent were withdrawn periodically and immediately filtered through $0.45 \mu \mathrm{m}$ pore size syringe filler. $\mathrm{COD}, \mathrm{NH}_{4}{ }^{+}-\mathrm{N}, \mathrm{NO}_{2}^{-}-\mathrm{N}, \mathrm{NO}_{3}^{-}-\mathrm{N}$ were determined according to the standard methods issued by the Environmental Protection Agency (EPA) of China (1989).

\section{RESULTS AND DISCUSSION}

\section{A. PAOs Incubation and Enrichment}

The SBR was initially operated with the mode of anaerobic/aerobic for 14 days (Period 1). At the beginning of the set up of the reactor, the ability of phosphorus removal was rather low, the phosphorus removal efficiency is only $51.3 \%$. Fig. 1 shows the profiles of $\mathrm{COD}$ and $\mathrm{PO}_{4}{ }^{3-}-\mathrm{P}$ during a cycle of SBR on the $3^{\text {rd }}$ day in period 1 . About ten days later, more than 90 of the phosphorus was removed by the reactor and its removal ratio were almost constant. The variations of COD and $\mathrm{PO}_{4}{ }^{3-}-\mathrm{P}$ in one cycle of SBR on the $14^{\text {th }}$ day are presented in Fig. 2. As seen in Figure I and Figure II, large quantities of COD were adsorbed and/or uptaken on activated sludge in the anaerobic phase in both cycles, the residual COD was therefore limited to aerobic stages. The two cycles differed in terms of $\mathrm{PO}_{4}{ }^{3-}-\mathrm{P}$ concentration in the end of cycle. The $\mathrm{PO}_{4}{ }^{3-}-$ $\mathrm{P}$ concentration was $4.87 \mathrm{mg} / \mathrm{L}$ on the $3^{\text {rd }}$ day and $0.25 \mathrm{mg} / \mathrm{L}$ on the $14^{\text {th }}$ day. The biological phosphorus system established so quickly, this was due to the seed sludge which was taken from the biological nutrient removal process.

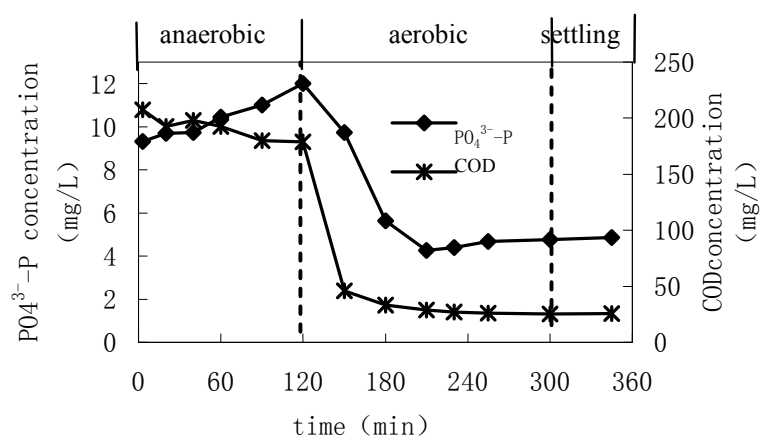

FIGURE I. VARIATION OF PHOSPHORUS AND COD CONCENTRATION IN A CYCLE ON THE $3^{\text {rd }}$ DAY

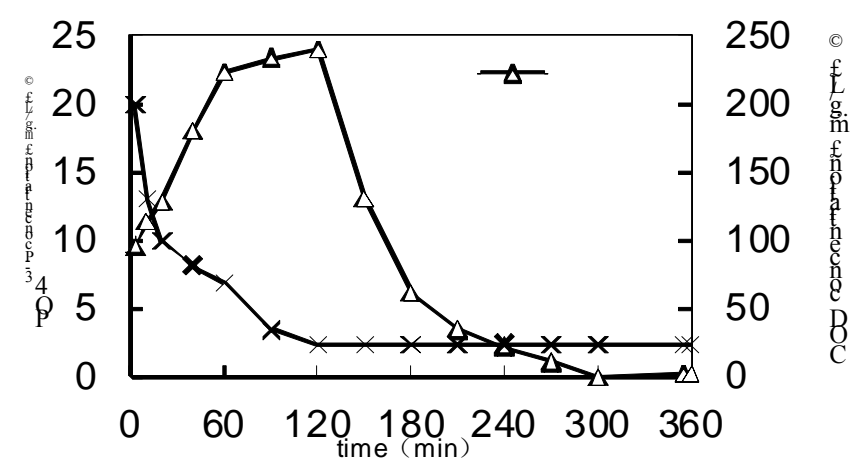

\section{FIGURE II. VARIATION OF PHOSPHORUS AND COD CONCENTRATION IN A CYCLE ON THE $14^{\text {th }}$ DAY}

\section{B. Phosphorus Removal Efficiency of DNPAOs}

The SBR was then operated with the mode of anaerobic/anoxic for 25 days (period 2). At the beginning of the anaerobic phase, the composition of synthetic wastewater was same as period 1 , and then sodium nitrate solution was adding to SBR in the end of anaerobic phase. The amount of phosphorus released in anaerobic phase, nitrite concentration, nitrate concentration and phosphorus concentration in effluent were monitored daily in the same cycle during the period 2. 
Figure III illustrated that the amount of $\mathrm{PO}_{4}{ }^{3-}-\mathrm{P}$ released in anaerobic period and effluent effect during the enrichment of DNPAOs. Phosphorus concentration, nitrite concentration and nitrate concentration were all high in the early days, this suggested that only a small part of $\mathrm{PAO}_{\mathrm{S}}$ have the ability of denitrifying phosphorus uptake in the SBR and the ability of utilizing nitrate as electron acceptor is poor, so a little amount of anoxic phosphorus accumulated in the system.

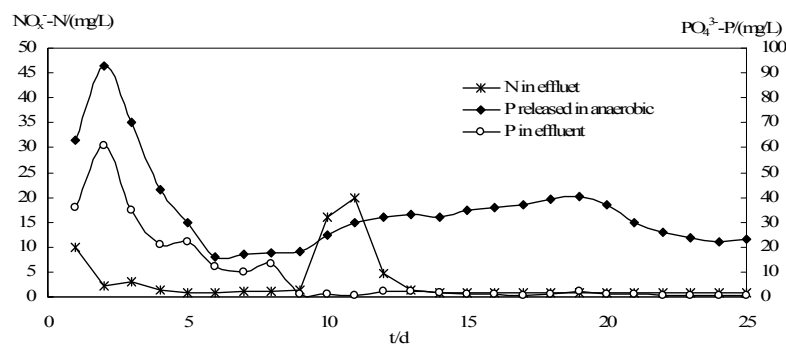

FIGURE III. ANAROBIC PHOSPHORUS RELEASE AND EFFECT IN THE COURSE OF DNPAOS CULTIVATION

During the first 12 days of operation in period 2, the concentrations of $\mathrm{PO}_{4}{ }^{3-}-\mathrm{P}, \mathrm{NO}_{2}^{-}-\mathrm{N}, \mathrm{NO}_{3}^{-}-\mathrm{N}$ in effluent were fluctuated, because of nitrate solution added not according to relation showed by equation 1.12 days later, sodium nitrate solution was added into SBR at the end of anaerobic according to equation 1 , the ability of $\mathrm{PAO}_{\mathrm{S}}$ using nitrate increased greatly, phosphorus concentration decreased rapidly in the effluent. the concentration of $\mathrm{PO}_{4}{ }^{3-}-\mathrm{P}$ decreased to $2 \mathrm{mg} / \mathrm{L}$ on the $18^{\text {th }}$ day, and the concentration of $\mathrm{PO}_{4}{ }^{3-}-\mathrm{P}$ decreased to $0.48 \mathrm{mg} / \mathrm{L}$ on the $25^{\text {th }}$ day, the sum of concentrations of $\mathrm{NO}_{2}^{-}-$ $\mathrm{N}$ and $\mathrm{NO}_{3}{ }^{-}-\mathrm{N}$ was only $0.78 \mathrm{mg} / \mathrm{L}$, the denitrifying phosphate accumulating efficiency reach to $95.2 \%$, the nitrogen removal efficiency reach to $96.1 \%$, the amount phosphorus released at the end of anaerobic was maintained at about $25 \sim 35 \mathrm{mg} / \mathrm{L}$, and there was a stable linear relation between the amount of phosphorus uptake and the consumption of nitrate in anoxic, the system had a strong ability to withstand loading shock and the system ran stably, denitrifying phosphorus accumulating system had been established. In this study, DNPAOs was rapidly induced and cultivated in SBR by regulating nitrate

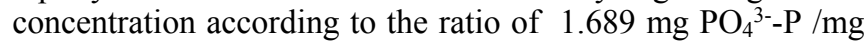
$\mathrm{NO}_{3}{ }^{-}-\mathrm{N}$ in anoxic time. While $\mathrm{Li}$ reported that denitrifying phosphors removal process was achieved after three months of acclimation[7].

\section{Batch Experiment}

To examine the fraction of DNPAO in $\mathrm{PAO}_{\mathrm{S}}$, the sludge with the ability of denitrifying phosphorus removal was taken from SBR to do batch experiment after anaerobic phase. The sludge was divided into two equal, and were put into two serum bottles. We labeled 1 and 2. Aerobic phosphorus removal efficiency was examined by pumping air to bottle1; anoxic phosphorus removal efficiency was investigated by adding nitrate solution to bottle 2.The experiment was done two times. One is at the time just before SBR cycle turned from anaerobic /aerobic to anaerobic /anoxic; the other is at the time when denitrifying phosphorus efficiency has reached over $95 \%$. Inducing efficiency of DNPAOS can be shown by comparing results in two batch experiments. Contrast of
Phosphorus uptake amount before and after induction of DNPAOs is presented in figure IV and figure $\mathrm{V}$.

As showed in figure IV and figure $V$, the curves of phosphorus uptake was in line with Monod curve, the maximum slope of curve was the rate of phosphorus uptake.

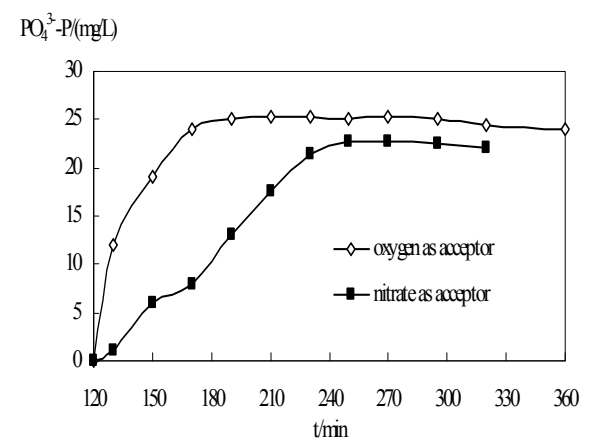

FIGURE IV. THE AMOUNT OF PHOSPHORUS UPTAKE BEFORE INDUCTION OF DNPAOs

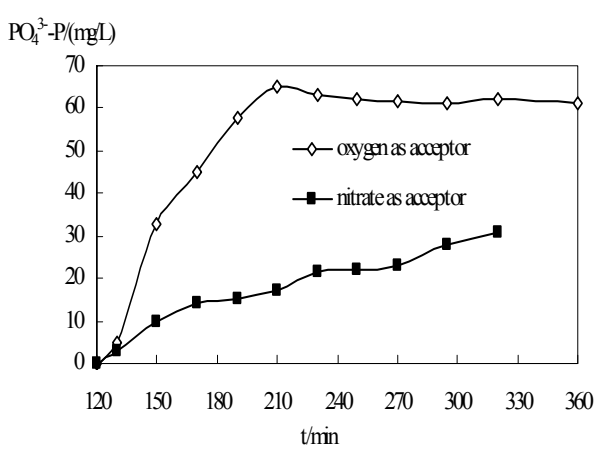

FIGURE V. THE AMOUNT OF PHOSPHORUS UPTAKE AFTER INDUCTION OF DNPAOs

During the period of anaerobic /aerobic and the beginning period of anaerobic / anoxic, the sludge in SBR had the same quality, we think they have the same quantity of PHB, what's more, oxygen and nitrate was enough, at that time, the rate of phosphorus uptake was maximum, and was proportional to the $\mathrm{PAO}_{\mathrm{S}}$ concentration. The relationship was illustrated in equation 2 and equation 3.

$$
\begin{aligned}
& r_{\max }=q X_{\text {nonDNPAO }} \\
& r_{\text {max }}^{\prime}=q^{\prime} X_{D N P A O}
\end{aligned}
$$

where

$r_{\max }$-Maximum phosphorus uptake rate of aerobic period, $\mathrm{mg} \mathrm{P} /(\mathrm{g} \mathrm{SS} \cdot \mathrm{h})$

$\mathbf{r}_{\text {max }}^{\prime}$-Maximum phosphorus uptake rate of anoxic period, $\mathrm{mg} \mathrm{P} /(\mathrm{g} \mathrm{SS} \cdot \mathrm{h})$ 
q-Phosphorus uptake rate constant of aerobic period, mg $\mathrm{P} /(\mathrm{g}$ non-DNPAO $\cdot \mathrm{h})$

q'-Phosphorus uptake rate constant of anoxic period, mg $\mathrm{P} /(\mathrm{g}$ DNPAO $\cdot \mathrm{h})$

$X$ non-DNPAO - the concentration of non-DNPAOs, $g$ non$\mathrm{DNPAO} / \mathrm{g} \mathrm{SS}$

$\mathrm{X}_{\mathrm{DNPAO}}$ - the concentration of Denitrifying Phosphate Accumulating Organisms, g DNPAO/g SS

DNPAOs and PAOs can exist simultaneously in the SBR, because the oxygen was exhausted in the inner of the activated sludge floc and oxygen also appeared in anoxic period. The relationship of DNPAOs and PAOs were presented in equation 4 and equation 7.

$$
\begin{gathered}
X_{\text {non-DNPAO }}+X_{\text {DNPAO }}=X_{P A O} \\
X_{\text {non-DNPAO }} / X_{\text {DNPAO }}=f_{\text {non-DNPAO }} \\
X_{\text {DNPAO }} / X_{\text {PAO }}=f_{\text {DNPAO }} \\
f_{\text {non-DNPAO }}+f_{\text {DNPAO }}=1
\end{gathered}
$$

where,

$\mathrm{X}_{\mathrm{PAO}}$ - the total concentration of phosphate accumulating organisms, g PAO/g SS

$\mathrm{f}_{\mathrm{DNPAO}}$ - the percentage of denitrifying phosphate accumulating organisms in the total phosphate accumulating organisms, $\%$

$\mathrm{f}_{\text {non- }}$ DNPAO - the percentage of aerobic phosphate accumulating organisms in the total phosphate accumulating organisms, $\%$

Kuba reported that energy generated by 1 mol NADH with nitrate as acceptor was $40 \%$ lower than with oxygen as acceptor[8], this means that rate of denitrifying phosphorus uptake was $60 \%$ of the rate of aerobic phosphorus uptake, so $\mathrm{q}^{\prime}$ was equal 0.6 times of $\mathrm{q}$. A new equation can be get by combining equation 2 , equation 3 and equation 7 :

$$
\frac{r_{\max }^{\prime}}{0.6} \bullet \frac{1}{r_{\max }}=\frac{f_{\text {DNPAO }}}{1-f_{\text {DNPAO }}}
$$

It can be estimated that the percentage of DNPAOs pre-and post induction in the total PAOs from eqation (8). As showed in Figure VI, the phosphate accumulating rate in aerobic condition was much faster than in anoxic condition. There was some nitrate in the system owing to the anoxic environment in the inner of activated sludge floc. Therefore there were already PAOs capable of utilizing both nitrate and oxygen as electron acceptor in system, although the cycle of SBR was anaerobic/aerobic. The maximum phosphorus uptake rate was $26.61 \mathrm{mgP} /(\mathrm{gSS} \cdot \mathrm{h})$. while the concentration of phosphorus decreased from $53.77 \mathrm{mg} / \mathrm{L}$ to $21.7 \mathrm{mg} / \mathrm{L}$ after anoxic period of 4 hours, the maximum phosphorus uptake rate was 6.09 $\mathrm{mgP} /(\mathrm{gSS} \cdot \mathrm{h})$. So the fraction of DNPAOs in PAOs can be calculated to 27 . $61 \%$. This ratio was higher than $11.2 \%$ reported by Lee [9].

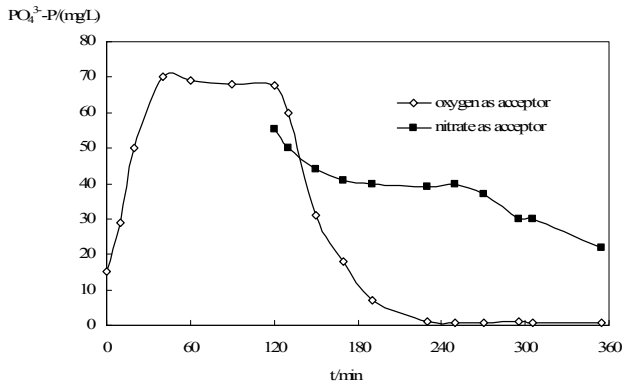

FIGURE VI. CURVE OF PHOSPHORUS UPTAKE IN AEROBIC OR ANAROBIC STAGE BEFORE INDUCTION OF DNPAOs

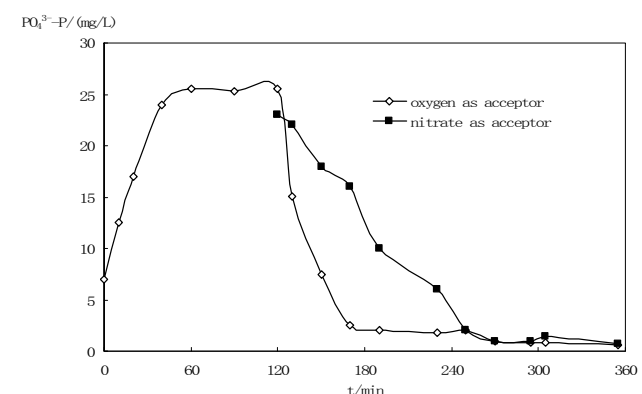

FIGURE VII. CURVE OF PHOSPHORUS UPTAKE IN AEROBIC OR ANAROBIC STAGE AFTER INDUCTION OF DNPAOs

Figure VII showed that the ability of denitrifying phosphorus removal of PAOs after induction. The phosphorus concentration in the effluent was $0.48 \mathrm{mg} / \mathrm{L}$ and the maximum phosphorus uptake rate was $21.98 \mathrm{mgP} /(\mathrm{gSS} \cdot \mathrm{h})$ when nitratewas utilized as acceptor; while the phosphorus concentration in the effluent was $0.40 \mathrm{mg} / \mathrm{L}$ and the maximum phosphorus uptake rate was $9.97 \mathrm{mgP} /(\mathrm{gSS} \cdot \mathrm{h})$ when oxygen was utilized as acceptor. So the fraction of DNPAOs in PAOs was $78.61 \%$.

\section{CONCLUSION}

Denitrifying phosphorus removal efficiency and nitrogen removal efficiency can be reached more than $95 \%$ and $96 \%$ respectively by adding nitrate concentration according to the ratio. The curve of phosphorus uptake was in line with Monod curve, the maximum slope of curve was the rate of phosphorus uptake, and was proportional to the concentration of PAOs. The calculated fraction of DNPAOs in PAOs increased from $27.61 \%$ to $78.61 \%$. High rate of denitrifying phosphorus uptake can be reached when the system was steady state; what's more it could higher than the rate of aerobic phosphorus uptake. 


\section{ACKNOWLEDGMENT}

The authors would like to thank the national natural science foundation of China (51408041), ministry of land and natural resources in arid and semi-arid areas of open water resources and environmental research laboratory.

\section{REFERENCES}

[1] Stoner D., Penn C., McGrath J., Warren J. 2012. "Phosphorus Removal with By-Products in a Flow-Through Setting,” J. Environ. Qual. 41: 654-663.

[2] Liu H.B., Zhu M.L., Gao S.S., Xia S.Q., Sun L.P.2014. "Enhancing denitrification phosphorus removal with a novel nutrient removal process: Role of configuration," Chemical Engineering Journal. 240: 404-412.

[3] Zeng R.J., Lemaire R., Yuan Z., Keller J. 2003. "Simultaneous nitrification, denitrification, and phosphorus removal in a lab-scale sequencing batch reactor," Biotechnol. Bioeng. 84: 170-178.

[4] Xu, X.Y., Liu, G., Zhu, L., 2011. "Enhanced denitrifying phosphorous removal in a novel anaerobic/aerobic/anoxic (AOA) process with the diversion of internal carbon source," Bioresour. Technol. 102: 1034010345.

[5] Kuba T., Van Loosdrecht M.C.M., Heijnen J.J. 1996. "Phosphorus and nitrogen removal with minimal COD requirement by integration of denitrifying dephosphatation and nitrification in a two-sludge system," Wat. Res. 30: 1702-1710.

[6] Wachtmeister A, Kuba T, van Loosdrecht M.C.M.1997. "A sludge characterization for aerobic and denitrifying phosphorus removing sludge," Wat. Res. 31: 471-478.

[7] Li C., Wang T., Zheng N., Zhang J., Ngo H.H., Guo W.S., Lia S. 2013. "Influence of organic shock loads on the production of $\mathrm{N}_{2} \mathrm{O}$ in denitrifying phosphorus removal process," Bioresource Technology 141:160-166.

[8] Kuba T., Wachtmeister A., Loosdrecht VanM CM.1994. “ Effect of nitrate on phosphorus release in biological phosphorus removal systems," Wat. Sci. \& Technol.,1994, 30: 263 - 269.

[9] Lee D. S., Jeon C. O., Park J. M. 2001. "Biological nitrogen removal with enhanced phosphate uptake in a sequencing batch reactor using single sludge system,” Wat. Res, 35: 3968- 3976. 